\title{
Per 4.0 Milliliters
}

National Cancer Institute

\section{Source}

National Cancer Institute. per 4.0 Milliliters. NCI Thesaurus. Code C122197.

A volume unit equal to 4.0 milliliters used as a denominator to build a derived unit expressed as a ratio. 